\title{
Previous prenatal loss as a predictor of perinatal depression and anxiety
}

Emma Robertson Blackmore, Denise Côté-Arsenault, Wan Tang, Vivette Glover, Jonathan Evans, Jean Golding and Thomas G. O'Connor

\section{Background}

Prenatal loss, the death of a fetus/child through miscarriage or stillbirth, is associated with significant depression and anxiety, particularly in a subsequent pregnancy.

\section{Aims}

This study examined the degree to which symptoms of depression and anxiety associated with a previous loss persisted following a subsequent successful pregnancy.

\section{Method}

Data were derived from the Avon Longitudinal Study of Parents and Children cohort, a longitudinal cohort study in the west of England that has followed mothers from pregnancy into the postnatal period. A total of 13133 mothers reported on the number and conditions of previous perinatal losses and provided self-report measures of depression and anxiety at 18 and 32 weeks' gestation and at 8 weeks and 8,21 and 33 months postnatally. Controls for pregnancy outcome and obstetric and psychosocial factors were included.

\section{Results}

Generalised estimating equations indicated that the number of previous miscarriages/stillbirths significantly predicted symptoms of depression $(\beta=0.18$, s.e. $=0.07, P<0.01)$ and anxiety $(\beta=0.14$, s.e. $=0.05, P<0.01$ ) in a subsequent pregnancy, independent of key psychosocial and obstetric factors. This association remained constant across the preand postnatal period, indicating that the impact of a previous prenatal loss did not diminish significantly following the birth of a healthy child.

\section{Conclusions}

Depression and anxiety associated with a previous prenatal loss shows a persisting pattern that continues after the birth of a subsequent (healthy) child. Interventions targeting women with previous prenatal loss may improve the health outcomes of women and their children.

\section{Declaration of interest}

None.
Pregnancy loss associated with miscarriage or stillbirth is common, affecting more than an estimated 1 million women in the USA and 70 000-90 000 women in the UK each year. ${ }^{1}$ Between 14 and $20 \%$ of clinically recognised pregnancies end in miscarriage, ${ }^{2}$ defined as the loss of an intrauterine pregnancy from natural causes before the 24th (in the UK) or 20th (in the USA) week of pregnancy. Stillbirth, or the loss of a pregnancy prior to delivery after the 20th week (USA) or 24th week (UK) of gestation due to natural causes, is estimated to occur in nearly 1 in 200 pregnancies. ${ }^{3,4}$ There is significant psychological/psychiatric morbidity associated with prenatal loss. Women exhibit significantly elevated levels of depression and anxiety in the weeks and months following the loss, compared with samples of pregnant, community or postpartum women. ${ }^{5-10}$ Between 50 and $80 \%$ of women who experience prenatal loss become pregnant again. ${ }^{11-14}$ That is significant because women with a history of prenatal loss are consistently reported to exhibit significantly elevated rates of anxiety and depressive symptoms during a subsequent pregnancy. ${ }^{14-18}$ What is not clear from existing studies of the impact of prenatal loss is whether or not symptoms associated with a previous loss persist beyond the birth of a subsequent (healthy) child (see also Hughes et al, ${ }^{14}$ Armstrong et $a l,{ }^{18}$ Hunfeld et $a l^{19}$ ). That is, does the birth of a healthy baby resolve the affective symptoms associated with previous loss or do the symptoms persist? Prior research has been unable to answer this important question because of limited follow-up periods, small sample sizes, selection biases, lack of control groups and lack of data on subsequent birth outcomes that may alter postnatal adjustment. The current study capitalised on a large community sample (Avon Longitudinal Study of Parents and Children (ALSPAC)) that had several research design advantages that allowed us to differentiate between two competing hypotheses with substantial clinical and public health significance: a history of prenatal loss would be associated with elevated depressive and anxiety symptoms that would be limited to the prenatal period, i.e. the birth of a healthy child would resolve the impact of the previous loss; and a history of prenatal loss would have a persisting effect on depressive and anxiety symptoms that extended beyond the birth of a subsequent healthy child.

\section{Method}

\section{Data}

Data for this study were obtained as part of ALSPAC, an ongoing population-based study designed to investigate the effects of a wide range of influences on the health and development of children.

\section{Study population}

Pregnant women residing in the Avon area of south-west England who had an estimated date of delivery between 1 April 1991 and 31 December 1992, were invited to participate in the study. It was estimated that $85-90 \%$ of the eligible population participated. ${ }^{20}$ All data used for this study were collected via postal questionnaires. The study cohort consisted of 14541 pregnancies and 13998 children who were still alive at 12 months of age. The study protocol has been published previously, ${ }^{20}$ and further details can be found at: www.bris.ac.uk/alspac. Ethical approval for all measures was obtained from the ALSPAC Ethics and Law Committee and from local research ethics committees. The current study focuses on the 13133 women for whom we had data on previous prenatal loss. The data for the current study are based on six assessments, two during pregnancy at 18 and 32 weeks' 
gestation, and four in the postpartum period, at 8 weeks and 8,21 and 33 months.

\section{Measures}

Prenatal loss

At the assessment at 18 weeks' gestation, respondents were asked to report the number of previous miscarriages and the number of previous stillbirths that they had experienced. Although the terms 'miscarriage' and 'stillbirth' were not explicitly defined, in the UK a stillbirth certificate is issued where there was a prenatal death after 24 weeks' gestation; accordingly, respondents who did experience a stillbirth would have had that document to designate formally a stillbirth. We also collected data on the number of previous elective terminations; these were counted separately.

\section{Anxiety}

Maternal anxiety at each occasion was measured using the anxiety items from the Crown-Crisp Experiential Index (CCEI), a validated self-rating inventory. ${ }^{21}$ It has been shown to correlate with the State (0.70) and Trait (0.76) subscales of the Spielberger State-Trait Anxiety Inventory. ${ }^{22}$ There is no established clinical cut-off, and so for categorical analyses we defined a mother as anxious if she scored in the top $15 \%$ of the sample.

\section{Depression}

Depression was assessed using the Edinburgh Postnatal Depression Scale (EPDS), a 10-item self-report questionnaire that has been extensively used and shown to be valid in and outside the postnatal period. ${ }^{23}$ A cut-off score of $\geqslant 12$ is recommended to identify cases of probable major depression. ${ }^{24}$

\section{Covariates}

A series of covariates were chosen because of their known links with depression and/or anxiety or because they were thought a priori to be a possible confound linking prenatal loss and depressive and anxiety symptoms. Specific covariates included maternal age at initial interview, currently living with husband or partner, number of living children, education level, ethnicity and use of tobacco and alcohol during the first 3 months of the pregnancy. Respondents were also asked 'Have you ever had a severe depression?' Those who answered 'yes, in the past not now' were classified as having a previous depressive episode. Birth weight was used as an indicator of healthy birth outcome; we dichotomised weight into $\leqslant 2500 \mathrm{~g}$ or $>2500 \mathrm{~g}$ representing low or normal birth weight. Gestational age at birth was dichotomised into $<32$ weeks or $>32$ weeks. A household crowding index was ascertained, which represents the number of residents per room. A high crowding index score is well established as an indicator of low socioeconomic status, a highly stressful situation, and is associated with high morbidity and mortality risks in a range of health outcomes. ${ }^{25}$

\section{Statistical analysis}

Generalised estimating equations (or GEE) is a method used for longitudinal data modelling. This method is semi-parametric and therefore does not require normal distribution assumptions to be met. Given that depression and anxiety can be treated as discrete or continuous data they do not meet normality assumptions for parametric data analysis. The GEE was performed to model the change of depression and anxiety over time. A backward elimination procedure was applied to control covariates and interactions. It should be noted that there were a significant number of missing values for depression and anxiety, especially for the last two visits. Specifically, sample sizes at the six visits were $12121,12096,11710,11195,10259$ and 9683. The impact of missing data was characterised by model estimates through two well-established missing data mechanisms: the missing completely at random assumption and the missing at random assumption. ${ }^{26}$ The missing completely at random assumption was tested by modelling the missingness as a function of observed responses and baseline covariates using logistic regression. It was found that depression at previous visit was a strong predictor, thus the missing completely at random assumption is inappropriate and weighted generalised estimating equations (WGEE) were used with weights estimated from the logistic model for missing data. ${ }^{26}$

\section{Results}

Online Table DS1 provides descriptive data on the sample. The majority ( $n=10310,79 \%$ ) of women reported no miscarriages. Rates of previous stillbirths were low, with $n=106 \quad(0.8 \%)$ reporting one and just three women reporting two prior stillbirths.

The first analysis examined whether stillbirths predicted subsequent depressive and anxiety symptoms more strongly than miscarriage. The non-parametric Wilcoxon rank sum test was applied to each visit to check whether there was any difference in depression and anxiety symptom scores between mothers who experienced a previous miscarriage and mothers who experienced a previous stillbirth. Results indicated that the difference between stillbirth and miscarriage was not significant $(P=0.27)$. Thus, stillbirth and miscarriage were combined in the analyses below.

Figure 1(a) and (b) present the mean (95\% CI) scores of depressive and anxiety symptoms across the assessment period according to the number of previous losses (miscarriages and stillbirths).

Table 1 presents results from the GEE model. Results indicate that, as expected, many of the psychosocial and sociodemographic covariates were associated with depressive and anxiety symptom scores. In addition, there was a significant prediction from the number of prenatal losses for both depressive and anxiety symptom scores. The magnitude of the effect was moderate: for each additional prenatal loss there was a corresponding increase of approximately one-quarter of a standard deviation in mood symptoms. Analyses to test the hypothesis that previous prenatal loss was a stronger predictor for pre- than postnatal assessments was carried out using an interaction between time of assessment and prenatal loss. For neither depressive nor anxiety symptoms was there an interaction between time of assessment and prenatal loss; that is, the association between prenatal loss and depressive and anxiety symptoms was not significantly different across the pre- and postnatal assessments (the interactions are not included in the final models in Table 1).

Table 2 shows the percentage and number of women who scored greater than 12 on the EPDS, which is indicative of a case of probable major depression, grouped by the number of losses.

\section{Supplementary analyses}

Analyses were re-run using categorical cut-off scores for depression and anxiety rather than a continuous scale. We found substantively comparable results using this alternate scaling. Given the overlap between depressive and anxious symptoms across the reproductive period, a final set of regression analyses (not reported; details available from the author) was carried out to investigate whether the effect of prenatal loss on anxious 
(a)
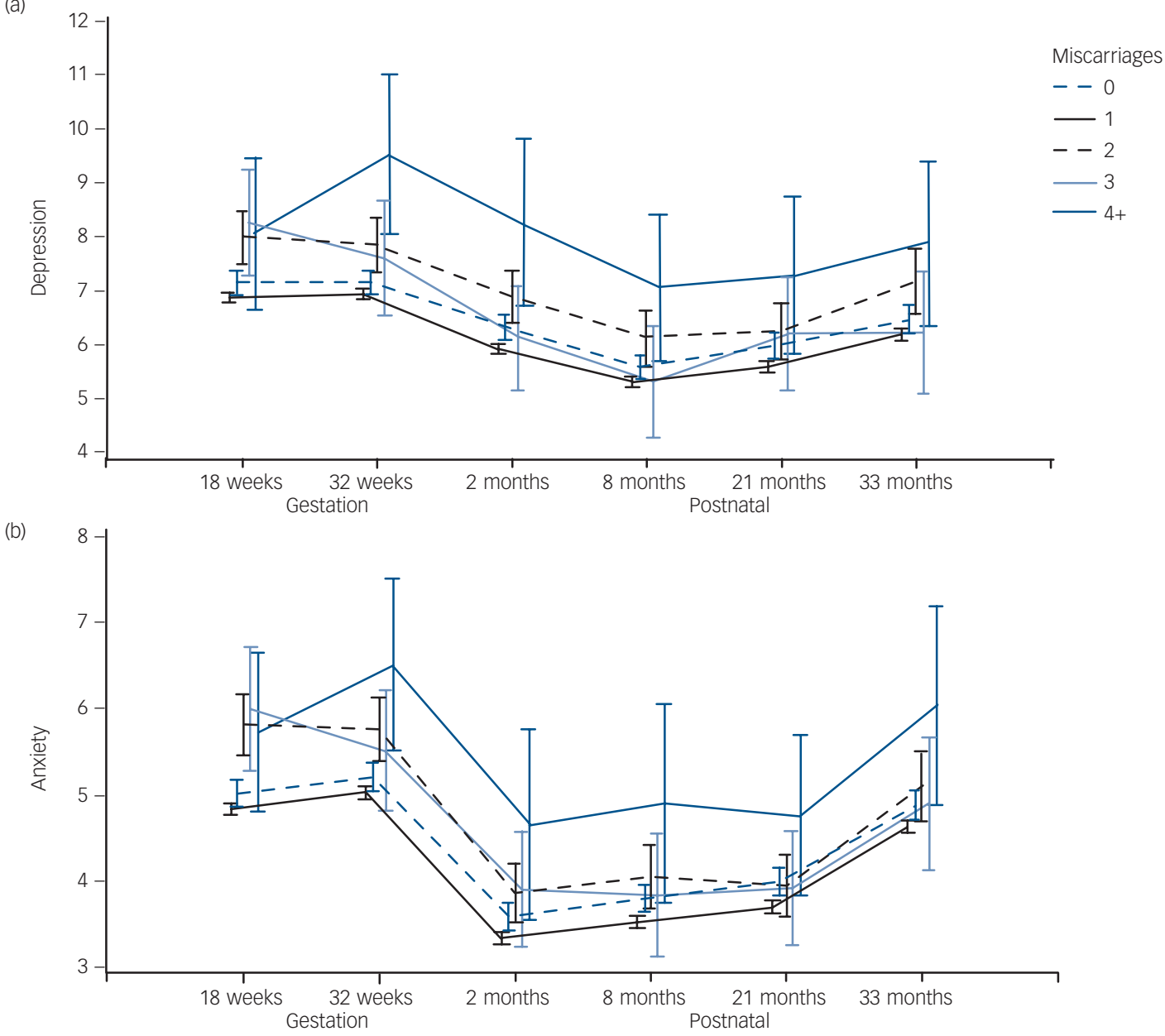

Fig. 1 Mean $(95 \% \mathrm{Cl})$ of (a) depression and (b) anxiety symptom scores throughout the perinatal period according to number of previous prenatal losses (miscarriages + stillbirths).

Numbers of participants are as follows: zero losses, $n=10250$; one, $n=2158$; two, $n=515$; three, $n=131$; and four or more, $n=79$.

symptoms was distinguishable from that for depressive symptoms and vice versa. It was not. The association between prenatal loss and anxious symptoms was confounded by the association between prenatal loss and depressive symptoms and the high degree of covariation between anxious and depressive symptoms $(>r=0.70$ at each assessment).

\section{Discussion}

\section{Main findings}

We found no evidence that affective symptoms associated with previous prenatal loss resolve with the birth of a healthy child. Rather, previous prenatal loss showed a persisting prediction of depressive and anxiety symptoms well after what would conventionally be defined as the postnatal period. There were changes over time in the perinatal period in depression and anxiety, but these did not vary significantly for women with different histories of prenatal loss. The predictions of anxious and depressive symptoms were similar and inseparable, the result of comparable effect sizes and the high degree of overlap between the two dimensions. Previous studies had documented that women who had experienced miscarriage or stillbirth had significantly higher levels of anxiety and depression in a subsequent pregnancy. $5,9,6,27$ The current study extends this work by showing that the impact persists well past the subsequent pregnancy and despite the birth of a healthy child (indexed here by birth weight and gestational age of the subsequent child).

\section{Findings from other studies}

Our findings of prolonged and elevated depressive and anxious symptoms in women with a prior prenatal loss nearly 3 years after the birth of a subsequent child contrast with some previous studies. Hughes et $a l^{14}$ found that, compared with controls, women who were pregnant subsequent to a stillbirth had significantly higher levels of depression and state anxiety during pregnancy, but did not differ from controls at 6 and 26 weeks postpartum. Interestingly, the subset of women who conceived less than a year following the stillbirth had significantly higher depression and anxiety scores across all time points than women who conceived after a year. The possibility that time since previous prenatal loss moderates the persisting impact of distress could not be examined in this study because we did not have reliable information on the timing of the previous loss. It may be that a more recent loss is associated with higher levels of affective symptoms that continue in the postpartum period, perhaps as a function of bereavement. ${ }^{6,14}$

Although Armstrong et al $^{18}$ also reported that depressive and anxious symptoms during pregnancy decreased following the birth of a healthy child, they noted that mothers with higher levels 
Table 1 Regression analyses predicting depression and anxiety symptoms from previous prenatal losses and covariates

\begin{tabular}{|c|c|c|c|c|c|c|c|c|}
\hline & \multicolumn{4}{|c|}{ Depression } & \multicolumn{4}{|c|}{ Anxiety } \\
\hline & $\beta$ & s.e. & $95 \% \mathrm{Cl}$ & $P$ & $\beta$ & s.e. & $95 \% \mathrm{Cl}$ & $P$ \\
\hline Tobacco smoked in first 3 months of pregnancy & & & & $<0.0001$ & & & & $<0.0001$ \\
\hline Yes & 0.69 & 0.11 & 0.46 to 0.91 & & 0.47 & 0.08 & 0.31 to 0.63 & \\
\hline No & 0.00 & 0.00 & 0.00 to 0.00 & - & 0.00 & 0.00 & 0.00 to 0.00 & - \\
\hline Previously experienced depression & & & & $<0.0001$ & & & & $<0.0001$ \\
\hline Yes & 3.17 & 0.19 & 2.80 to 3.54 & & 2.65 & 0.13 & 2.39 to 2.91 & \\
\hline No & 0.00 & 0.00 & 0.00 to 0.00 & - & 0.00 & 0.00 & 0.00 to 0.00 & - \\
\hline Alcohol consumption in the first 3 months of pregnancy & & & & 0.0001 & & & & 0.0002 \\
\hline Never & 0.00 & 0.00 & 0.00 to 0.00 & & 0.00 & 0.00 & 0.00 to 0.00 & \\
\hline$<1$ glass per week & 0.28 & 0.09 & 0.10 to 0.45 & & 0.18 & 0.06 & 0.05 to 0.37 & \\
\hline 1+ glass per week & 0.41 & 0.13 & 0.16 to 0.66 & & 0.26 & 0.09 & 0.07 to 0.44 & \\
\hline $1-2$ glasses per day & 0.94 & 0.40 & 0.16 to 1.73 & & 0.79 & 0.27 & 0.25 to 1.32 & \\
\hline $3+$ glasses per day & 4.12 & 1.26 & 1.64 to 6.59 & & 2.71 & 0.88 & 0.99 to 4.43 & \\
\hline Crowding index & 0.29 & 0.06 & 0.17 to 0.41 & $<0.0001$ & 0.21 & 0.04 & 0.12 to 0.29 & $<0.0001$ \\
\hline Maternal age & -0.04 & 0.01 & -0.06 to -0.02 & $<0.0001$ & -0.02 & 0.00 & -0.04 to -0.01 & 0.0012 \\
\hline Number of living children & 0.18 & 0.06 & 0.06 to 0.30 & $<0.0001$ & 0.05 & 0.04 & -0.03 to 0.14 & 0.18 \\
\hline Currently living with partner & & & & $<0.0001$ & & & & $<0.0001$ \\
\hline Husband & 0.00 & 0.00 & 0.00 to 0.00 & & 0.00 & 0.00 & 0.00 to 0.00 & $<0.0001$ \\
\hline Other male & 0.66 & 0.12 & 0.43 to 0.89 & & 0.53 & 0.08 & 0.36 to 0.70 & \\
\hline None & 0.53 & 0.35 & -0.16 to 1.22 & & 0.25 & 0.25 & -0.24 to 0.75 & \\
\hline Other & 2.20 & 0.83 & 0.57 to 3.83 & & 1.33 & 0.49 & 0.35 to 2.30 & \\
\hline Maternal level of education & -0.03 & 0.03 & -0.11 to 0.03 & 0.31 & 0.05 & 0.02 & 0.00 to 0.10 & 0.05 \\
\hline Number of perinatal losses & 0.18 & 0.07 & 0.03 to 0.32 & 0.01 & 0.14 & 0.05 & 0.03 to 0.24 & $<0.0001$ \\
\hline Visit & & & & $<0.0001$ & & & & $<0.0001$ \\
\hline 18 weeks' gestation & 0.00 & 0.00 & 0.00 to 0.00 & & 0.00 & 0.00 & 0.00 to 0.00 & \\
\hline 32 weeks' gestation & 0.09 & 0.04 & 0.01 to 0.18 & & 0.21 & 0.03 & 0.15 to 0.27 & \\
\hline 2 months postnatal & -0.83 & 0.05 & -0.93 to -0.72 & & -1.46 & 0.03 & -1.53 to -1.39 & \\
\hline 8 months postnatal & -1.44 & 0.05 & -1.55 to -1.34 & & -1.21 & 0.03 & -1.29 to -1.14 & \\
\hline 21 months postnatal & -1.08 & 0.06 & -1.20 to -0.96 & & -1.03 & 0.04 & -1.11 to -0.95 & \\
\hline 33 months postnatal & -0.57 & 0.06 & -0.70 to -0.44 & & -0.13 & 0.04 & -0.23 to -0.04 & \\
\hline Birth weight (for the current pregnancy) & & & & 0.02 & & & & 0.03 \\
\hline$\leqslant 2500 \mathrm{~g}$ & 0.57 & 0.26 & 0.06 to 1.08 & & 0.39 & 0.18 & 0.03 to 0.76 & \\
\hline$<2500 \mathrm{~g}$ & 0.00 & 0.00 & 0.00 to 0.00 & & 0.00 & 0.00 & 0.00 to 0.00 & \\
\hline
\end{tabular}

Table 2 Participants with an Edinburgh Postnatal Depression Scale score $>12$ grouped by number of losses and assessment point

\begin{tabular}{|lccccc|} 
& \multicolumn{5}{c|}{ Number of losses, \% (n) } \\
\cline { 2 - 6 } Assessment point & 0 & 1 & 2 & 3 & $4+$ \\
\hline 18 weeks' gestation & $13.3(1238)$ & $14.1(278)$ & $19.7(90)$ & $25.2(30)$ & $23.1(15)$ \\
\hline 32 weeks' gestation & $14.2(1305)$ & $15.4(293)$ & $20.3(90)$ & $22.7(25)$ & $34.4(22)$ \\
\hline 2 months postpartum & $9.3(819)$ & $11.6(217)$ & $17.0(74)$ & $11.3(12)$ & $21.3(13)$ \\
\hline 8 months postpartum & $8.2(690)$ & $9.8(174)$ & $12.4(50)$ & $9.7(10)$ & $17.5(10)$ \\
\hline 21 months postpartum & $9.2(713)$ & $11.5(188)$ & $12.6(47)$ & $13.2(12)$ & $15.1(8)$ \\
\hline 33 months postpartum & $11.9(876)$ & $12.7(194)$ & $18.6(66)$ & $10.1(8)$ & $21.3(10)$ \\
\hline
\end{tabular}

of depression and anxiety in the postpartum period reported increased concerns about their investment in and health concerns about their infant. This raises the important issue of how and whether previous perinatal loss and associated mood symptoms may alter child outcomes. Limited available data suggest that mothers may have more concerns about and greater difficulty managing the needs of a child born after a prenatal loss; ${ }^{19,28}$ also, 12-month-old infants born following prenatal loss were reported to show higher rates of disorganised attachment patterns to their mothers than children born into families without a loss history. ${ }^{29,30}$ Thus, even if there is no persistence of mood disturbance into the postnatal period, there may still be adverse effects of a previous prenatal loss on the parent-child relationship and child outcomes. This possibility requires further attention.

Brockington $^{31}$ has argued that pregnancy and childbirth should be seen as a general stressor, like any other life event that can potentially trigger an affective illness episode. ${ }^{32}$ The current findings underscore the view that pregnancy and childbirth are major life events, a careful assessment of which may reveal information of value in understanding psychiatric morbidity.

\section{Clinical implications}

There are important clinical implications of this work. Currently, prenatal loss is not routinely considered a risk factor for antenatal or postpartum depression in the same way as, for instance, personal or family history of depression, exposure to stressful life events or lack of social support. Our findings suggest that routinely assessing loss history, which could be accomplished briefly and without some of the report bias that accompanies other assessments, would be valuable as a predictor of current 
and postpartum risk and as a possible marker for intervention. Approximately $15 \%$ of women experience clinically significant antenatal depression and anxiety ${ }^{33}$ and so recognition of and effective treatment for perinatal mood disturbance are of the utmost importance. Both prenatal depression and anxiety are among the biggest predictors of postpartum depression, ${ }^{34,35}$ which in turn has deleterious effects on maternal-child attachment, child behaviour, and cognitive and neuroendocrine outcomes that persist into adolescence. ${ }^{36-40}$ Given the adverse outcomes of persistent maternal depression on both child and family outcomes, early recognition of symptoms can lead to preventive interventions to reduce the burden of illness, provide coping strategies to reduce anxiety and depression and promote healthy adjustment of the mother, family and child.

\section{Strengths and limitations}

Strengths of the study include the large community sample and detailed and repeated assessments of depressive and anxiety symptoms in the prenatal and postnatal period; the follow-up well past the postnatal period is a particular novelty in this area of study. There are, however, limitations. Participants were asked about the number of miscarriages and stillbirths experienced retrospectively, which could be subject to recall bias. However, the objective nature of the event provides some protection against this possibility, and the persistence of effect years after the enquiry about perinatal loss makes a simple recall bias account unlikely. Self-reports of prenatal loss may be underestimated insofar as mothers are often unaware of spontaneous early miscarriages. ${ }^{4}$ Accordingly, the current study is able to assess the psychological impact of prenatal loss, but is not positioned to examine biological hypotheses that there may be risk underlying both prenatal loss and the experience of depressive and anxiety symptoms. Finally, as noted, we were unable to assess the impact of time since loss as a potential predictor of postpartum mood.

Emma Robertson Blackmore, PhD, Department of Psychiatry, University of Rochester Medical Center, New York; Denise Côté-Arsenault, PhD, School of Nursing, University of Rochester Medical Center, New York; Wan Tang, PhD, Department of Biostatistics and Computational Biology, University of Rochester Medical Center, New York, USA; Vivette Glover, PhD, Institute of Reproductive and Developmental Biology, Imperial College School of Medicine, London, UK; Jonathan Evans, PhD, Academic Unit of Psychiatry, School of Social and Community Medicine, University of Bristol; Jean Golding, PhD, Centre for Child and Adolescent Health, University of Bristol, UK; Thomas G. O'Connor, PhD, Department of Psychiatry, University of Rochester Medical Center, New York, USA

Correspondence: Emma Robertson Blackmore, PhD, University of Rochester Medical Center, BOX PSYCH 4-9200, 300 Crittenden Blvd, Rochester,

NY 14642-8409, USA. Email: Emma_robertsonblackmore@urmc.rochester.edu

First received 26 May 2010, final revision 13 Oct 2010, accepted 9 Dec 2010

\section{Funding}

The UK Medical Research Council, the Wellcome Trust and the University of Bristol currently provide core support for ALSPAC. This particular project was funded in part by National Institutes of Health (NIH) grants R01 MH073842 and K23 MH080290.

\section{Acknowledgements}

We are extremely grateful to all the families who took part in this study, the midwives fo their help in recruiting them and the whole ALSPAC team, which includes interviewers, computer and laboratory technicians, clerical workers, research scientists, volunteers, managers, receptionists and nurses.

\section{References}

1 Wong MK, Crawford TJ, Gask L, Grinyer A. A qualitative investigation into women's experiences after a miscarriage: implications for the primary healthcare team. Br J Gen Pract 2003; 53: 697-702.
2 Farquharson RG, Jauniaux E, Exalto N, ESHRE Special Interest Group for Early Pregnancy (SIGEP). Updated and revised nomenclature for description of early pregnancy events. Hum Reprod 2005; 20: 3008-11.

3 Office for National Statistics. Birth Statistics 1996, England and Wales. Office for National Statistics, 1998.

4 Martin JA, Kochanek KD, Strobino DM, Guyer B, MacDorman MF. Annua summary of vital statistics-2003. Pediatrics 2005; 115: 619-34.

5 Janssen HJEM, Cuisinier MCJP, Hoogduin KALM, de Graauw KPHM. Controlled prospective study on the mental health of women following pregnancy loss. Am J Psychiatry 1996; 153: 226-30.

6 Beutel M, Deckardt R, Von RM, Weiner H. Grief and depression after miscarriage: their separation, antecedents, and course. Psychosom Med 1995; 57: 517-26.

7 Neugebauer R, Kline J, Shrout P, Skodol A, O'Connor P, Geller PA, et al. Major depressive disorder in the 6 months after miscarriage. JAMA 1997; 277: 383-8.

8 Neugebauer R, Kline J, O'Connor P, Shrout P, Johnson J, Skodol A, et al. Depressive symptoms in women in the six months after miscarriage. Am J Obstet Gynecol 1992; 166: 104-9.

9 Thapar AK, Thapar A. Psychological sequelae of miscarriage: a controlled study using the general health questionnaire and the hospital anxiety and depression scale. Br J Gen Pract 1992; 42: 94-6.

10 Lok IH, Yip AS, Lee DT, Sahota D, Chung TK. A 1-year longitudinal study of psychological morbidity after miscarriage. Fertil Steril 2010; 93: 1966-75.

11 Cordle CJ, Prettyman RJ. A 2-year follow-up of women who have experienced early miscarriage. J Reprod Infant Psychol 1994; 12: 37-43.

12 Garel M, Blondel B, Lelong N, Bonenfant S, Kaminski M. Long-term consequences of miscarriage: the depressive disorders and the following pregnancy. J Reprod Infant Psychol 1994; 12: 233-40.

13 Wolff JR, Nielson $\mathrm{PE}$, Schiller $\mathrm{P}$. The emotional reaction to a stillbirth. Am J Obstet Gynecol 1970; 108: 73-7.

14 Hughes PM, Turton $\mathrm{P}$, Evans $\mathrm{CD}$. Stillbirth as risk factor for depression and anxiety in the subsequent pregnancy: cohort study. BMJ 1999; 318: 1721-4

15 Côté-Arsenault $D$. The influence of perinatal loss on anxiety in multigravidas. J Obstet Gynecol Neonatal Nurs 2003; 32: 623-9.

16 Theut SK, Pedersen FA, Zaslow MJ, Rabinovich BA. Pregnancy subsequent to perinatal loss: parental anxiety and depression. J Am Acad Child Adolesc Psychiatry 1988; 27: 289-92.

17 Franche RL, Mikail SF. The impact of perinatal loss on adjustment to subsequent pregnancy. Soc Sci Med 1999; 48: 1613-23.

18 Armstrong DS, Hutti MH, Myers J. The influence of prior perinatal loss on parents' psychological distress after the birth of a subsequent healthy infant. J Obstet Gynecol Neonatal Nurs 2009; 38: 654-66.

19 Hunfeld JA, Taselaar-Kloos AK, Agterberg G, Wladimiroff JW, Passchier J. Trait anxiety, negative emotions, and the mothers' adaptation to an infant born subsequent to late pregnancy loss: a case-control study. Prenat Diagn 1997; 17: 843-51.

20 Golding J, Pembrey M, Jones R. ALSPAC - the Avon Longitudinal Study of Parents and Children. I. Study methodology. Paediatr Perinat Epidemiol 2001; 15: 74-87.

21 Birtchnell J, Evans C, Kennard J. The total score of the Crown-Crisp Experiential Index: a useful and valid measure of psychoneurotic pathology. Br J Med Psychol 1988; 61: 255-66.

22 Spielberger CD. State-Trait Anxiety Inventory: A Comprehensive Bibliography. Consulting Psychological Press, 1984.

23 Cox JL, Holden JM, Sagovsky R. Detection of postnatal depression. Development of the 10-item Edinburgh Postnatal Depression Scale. Br J Psychiatry 1987; 150: 782-6.

24 Murray D, Cox J. Screening for depression during pregnancy with the Edinburgh depression scale (EPDS). J Reprod Infant Psychol 1990; 8: 99-107.

25 Melki IS, Beydoun HA, Khogali M, Tamim H, Yunis KA, National Collaborative Perinatal Neonatal Network (NCPNN). Household crowding index: a correlate of socioeconomic status and inter-pregnancy spacing in an urban setting. J Epidemiol Community Health 2004; 58: 476-80.

26 Robins JM, Rotnitzky A, Zhao LP. Analysis of semiparametric regression models for repeated outcomes in the presence of missing data. J Am Stat Assoc 1995; 90: 106-21.

27 Armstrong $D$, Hutti M. Pregnancy after perinatal loss: the relationship between anxiety and prenatal attachment. J Obstet Gynecol Neonatal Nurs 1998; 27: 183-9.

28 Theut SK, Moss HA, Zaslow MJ, Rabinovich BA, Levin L, Bartko JJ. Perinata loss and maternal attitudes towards the subsequent child. Infant Ment Health J 1992; 13: 157-166. 
29 Heller SS, Zeanah $\mathrm{CH}$. Attachment disturbances in infants born subsequent to perinatal loss: a pilot study. Infant Ment Health J 1999; 20: 188-99.

30 Hughes $\mathrm{P}$, Turton $\mathrm{P}$, Hopper E, McGauley GA, Fonagy P. Disorganised attachment behaviour among infants born subsequent to stillbirth. $J$ Child Psychol Psychiatry 2001; 42: 791-801.

31 Brockington IF. Motherhood and Mental Health. Oxford University Press, 1996.

32 Brown GW, Harris TO, Hepworth C. Life events and endogenous depression. A puzzle reexamined. Arch Gen Psychiatry 1994; 51: 525-34.

33 Heron J, O'Connor TG, Evans J, Golding J, Glover V. The course of anxiety and depression through pregnancy and the postpartum in a community sample. $J$ Affect Disord 2004; 80: 65-73.

34 Robertson E, Grace S, Wallington T, Stewart DE. Antenatal risk factors for postpartum depression: a synthesis of recent literature. Gen Hosp Psychiatry 2004; 26: 289-95.

35 O'Hara MW, Swain AM. Rates and risk of postpartum depression - a meta analysis. Int Rev Psychiatry 1996; 8: 37-54.
36 Halligan SL, Herbert J, Goodyer I, Murray L. Disturbances in morning cortisol secretion in association with maternal postnatal depression predict subsequent depressive symptomatology in adolescents. Biol Psychiatry 2007; 62: $40-6$.

37 Halligan SL, Murray L, Martins C, Cooper PJ. Maternal depression and psychiatric outcomes in adolescent offspring: a 13-year longitudinal study. J Affect Disord 2007; 97: 145-54.

38 Murray L, Halligan SL, Adams G, Patterson P, Goodyer IM. Socioemotional development in adolescents at risk for depression: the role of maternal depression and attachment style. Dev Psychopathol 2006; 18: 489-516.

39 Bergman K, Glover V, Sarkar P, O'Connor TG. Maternal prenatal cortisol and infant cognitive development: moderation by infant-mother attachment. Biol Psychiatry 2010; 67: 1026-32.

40 O'Connor TG, Heron J, Golding J, Beveridge M, Glover V. Maternal antenatal anxiety and children's behavioural/emotional problems at 4 years: report from the Avon Longitudinal Study of Parents and Children. Br J Psychiatry 2002; 180: 502-8

\section{Neil Aggarwal}

Little is known about the life of Ahmed ibn 'Umar ibn 'Alî, better known as Nizâmî 'Arûzî. The only information resides in his own text outlining travels throughout Uzbekistan and Afghanistan to collect biographies of famous poets. He reached Iran and became the court poet of the sultan Sanjar in 1116/1117 AD. His monumental Chahâr Maqâle (Four Discourses) addresses the four professions indispensable for a sound ruler: poet, civil secretary, astrologer and physician. The work entered the literary canon within the 13 th century.

Four Discourses is rich in cultural history. For example, 'Arûzî lists essential works for the mastery of medicine. Moreover, his narratives resemble case presentations. Contemporary readers can therefore compare symptoms across time and space.

In one anecdote on melancholia, a person dear to the Buyid ruler 'Alâ al-Dawla becomes so delusional that he considers himself a cow. He asks people to kill and eat him even as he fasts. Since no physician could treat him, the ruler entreats his trusted vizier Ibn Sîna (Avicenna), who dispatches two men with word of a butcher's arrival. The young man rejoices. As they bind his limbs, Ibn Sîna inspects him like a butcher, but protests that he is too thin for slaughter. Ibn Sinna orders specific foods and medicines to fatten him up. The young man cheerfully obliges. Ibn Sîna continues to consult and within a month the man's health returns.

Notable lessons can be drawn from this anecdote. Like today, one millennium ago physicians struggled to manage psychotic depression. Ibn Sîna's status as minister also reveals the historical esteem of physicians. Finally, physicians working within the patient's psychological world tend to succeed, even through unorthodox means. This helps explain Ibn Sîna's lasting reputation. 